\title{
Discussion of the Structural Irregularities in the Plan for Architectural Design within the Scope of Earthquake Codes
}

\author{
Zeynep Yeşim İlerisoy ${ }^{*}$ \\ ${ }^{1}$ Department of Architecture, Faculty of Architecture, Gazi University, Eti Mah., Yükseliş Sok., No:5, Maltepe, \\ 06560 Ankara, Turkey \\ * Corresponding author, e-mail: zyharmankaya@gazi.edu.tr
}

Received: 31 August 2018, Accepted: 31 January 2019, Published online: 05 March 2019

\begin{abstract}
Earthquake codes are legal documents that set the minimum conditions for the construction of seismically safe buildings, and each country has different restrictions under different subheadings, depending on the seismic history of the region and the economic situation of the country. The biggest contribution to architectural design in earthquake codes is under the heading of "structural irregularity". If the design of a structure is regular, the behaviour of the structure under the earthquake effect becomes more rational, the resistance against the dynamic loads of the structure is increased, resulting in a better economic performance compared to the irregular buildings. To examine the visual expression techniques necessary for architects to be able to understand earthquake codes, eight different seismic codes for countries on active fault lines with different seismic histories were discussed, and it was revealed that limit values for irregularity definitions differed among them. The design decisions that will cause irregularities in the plan are considered comprehensively, and the precautions that can be taken against these irregularities are explained to architects in order to create awareness. In addition, because of the improved comprehension of visual forms in human perception, the subject is illuminated with simple but descriptive drawings. In conclusion, this study can be considered as a source for understanding regulations for seismic design, revealing information about architecture in the face of the ever-changing reality of an earthquake, and the possession of the tools that architects can use effectively in this regard.
\end{abstract}

Keywords

earthquake code, earthquake resistant design, horizontal structural irregularity

\section{Introduction}

Numerous earthquakes have occurred in countries that are on the most active fault lines in the world. In these regions, earthquakes have caused the loss of many lives and property, even though they have become common events (Allen, 2007). As a result of the experiences obtained, the design of the earthquake-resistant structure becomes a necessity to minimise the damage that occurs in these structures. The purpose of earthquake-resistant structure design, is to prevent the loss of life by ensuring that the load-bearing system remains undamaged or slightly damaged as a result of small-scale or largescale earthquakes, accordingly. The earthquake-resistant structure design comprises events that are generally uncertain. The most important uncertainty in this regard, is which discipline will carry out the design process of these structures. In general, there is widespread belief that the production of earthquake-resistant structures is related to the engineering profession (Özmen, 2008). However, examinations made after major earthquakes over the last 20 years have shown that this is not correct, and when building damage is examined, many structures have become unusable due to decisions made during the architectural design process (İnan and Korkmaz, 2011; Özmen, 2008; Öztürk, 2011).

Maver (1970) and Peña and Parshall (2001) defined architectural design as a trial-and-error process, which consists of several variables related to economy, aesthetics, functionality, and strength. The architectural design process is the stage of construction where the various features of the building are identified, and decisions are made concerning building characteristics that affect the building's structural behaviour. In this phase, earthquake-resistant structure design should be considered if the structures are constructed in regions of high earthquake risk. A suitable 
structural system for architectural and functional design is determined by architects during the preliminary design phase (İlerisoy and Tuna, 2018a). Architects need to comprehend the concepts of the necessary structural system and earthquake-resistant design to produce quality structures. Earthquakes usually cause damage to weak spots in the configuration of a building. If the decisions taken in the architectural design phase, which are crucial for the building's behaviour against earthquakes, are based on the right information and using the right methods, design success will be increased, and a long-lasting and sustainable structure against earthquakes will be achieved. At this point, it is possible to say that the most acceptable design of the earthquake-resistant structure can be achieved by the efforts of the architects. Architects should remember that in the configuration of a building, they will determine where the seismic damage should occur in the building (NZSEE, 2007).

Every country that has experienced major earthquakes has developed earthquake codes based on its own experiences regarding the implementation of design principles for earthquake-resistant structures. Earthquake codes are legal documents that set minimum conditions for the construction of seismically safe and functional buildings. The purpose of these codes is to prevent unfavourable conditions under the dynamic loading for the area where the structures are located, taking into account the earthquake risk. The seismic codes comprise a technical language and mostly address the working areas of civil engineers (Özmen and Ünay, 2007). However, since the structure of the building is formed during the architectural design stage and the general rules are provided by the architects, the codes should also be guiding technical specifications for the architects.

Earthquake codes, which are directly related to design and construction, address a wide area (analytical methods, reinforced concrete buildings, steel buildings, masonry buildings, foundations, evaluation and strengthening of existing buildings). At this point, it is useful to understand the philosophy of the codes according to the field of the person concerned. It is very important to understand the earthquake codes to reinterpret information about architecture in the case of an earthquake, which is an unchanging reality, to enable architects to use the right tools effectively in this matter.

In the earthquake codes, architectural design is mostly discussed under the title of "structural irregularity". Structural irregularities are the applications that negatively affect the behaviour or strength of the structure under static and dynamic loads. Structural irregularities may vary dramatically in their nature and in principle, are very difficult to define. However, in the simplest sense, irregular buildings are defined as insecure buildings with a poor performance against earthquakes (Harmankaya and Soyluk, 2012). Regarding buildings, for practical purposes, major seismic codes distinguish irregularities in plan (horizontal) and in elevation (vertical) (De Stefano and Pintucchi, 2008).

Seismic codes do not require regular building, although it is desirable to build regular buildings according to their definitions, only imposing a penalty on irregular buildings. This penalty method is mostly to refine the calculation methods and thus to increase dynamic forces on the structural elements. These different loading calculations allow designers to create irregular buildings that remain safe. However, the building cost, which is an important parameter in evaluating the function and performance of a building, is increased. Buildings differ from other sectors' products because they incur high costs and are unique and irreversible. Achieving a building at the most reasonable cost is crucial for many people or organisations involved in the construction sector, regarding making appropriate decisions and using the budget in the most efficient way (İlerisoy and Tuna, 2018a).

In this study, the aim is to create a consciousness about how design decisions are handled in available earthquake codes and to provide a guiding resource for architectural disciplines regarding irregularities, which are often inevitable because of building use and architectural necessities.

\section{Method}

Since earthquake codes address a wide area, the study is restricted to explanations under the title of "structural irregularity", which is closely related to architectural design. Structural irregularities can be divided into two groups as horizontal and vertical irregularities. In this study, limitations on the structural irregularities in plan (horizontal) have been investigated. The most common use of creativity in the planning and application phases of a structure is, of course, the configuration of the plan geometry and then the functional solutions.

For this reason, horizontal irregularities due to decisions made on the plan are the limitations that must be taken into account in the first stage of architectural design. Horizontal irregularities, which both make buildings vulnerable to lateral forces and cause additional increases in terms of cost, are not completely forbidden in the earthquake codes but are put under deterrent conditions. Most of the horizontal irregularities are defined only according to 
the physical properties of the building. The purpose of this study is to evaluate the limits of the plan irregularities. First, a comprehensive classification of the irregularities caused by the design decisions in the plan was made.

In this study, the current seismic codes data of the countries in the official website of the International Association for Earthquake Engineering (IAEE) were utilised. Regarding the examined codes, earthquake codes written only in the language of that country (Croatia, Pakistan, Singapore, Armenia, Ukraine, Canada and Montenegro), and codes that are inaccessible on the internet (Spain, Ecuador, Russia, Colombia, Thailand, Dominic Republic, Colombia) were not investigated in this study. Also, the contents of the seismic codes are also different. For example, since, in the codes of Nepal, Argentina, Romania, Ghana, Uganda, Switzerland, Egypt, Taiwan, Nicaragua and Japan, structural irregularities are not mentioned, these codes are not investigated in this study. As a result, in this study, codes of the countries with different seismic experiences; Turkey (AFAD, 2018), China (MOHURD, 2010), Iran (BHRC, 2007), New Zealand (NZSEE, 2014), Mexico (FDGM, 1995), India (BIS, 2002) and earthquake code of the European Union countries located on active fault lines, (Eurocode-8 (CEN, 2004)) and ASCE/SEI 7-10 (ASCE, 2016), have been examined in detail (Fig. 1). Definitions of irregularities in the seismic codes are tabulated and compared. Thus, the study, which deals with eight codes in total, reveals the intersection points and differences in descriptions resulting from different experiences.

After graduating from university, architects in working life expressed that they faced a "wall" when it came to earthquake codes, which were never mentioned in their education (Ankara Chamber of Architects, 2007). Understanding, learning and overcoming this wall is a prerequisite for every architect. The greatest challenge for individuals facing earthquake codes is to interpret the limitations introduced by definitions and formulas and effectively integrate them into the product design in the

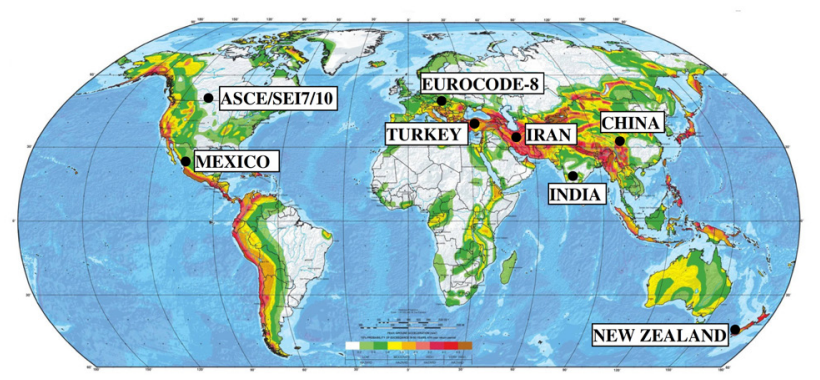

Fig. 1 Map of global seismic hazards and countries covered by the study (Alden, 2017) architectural design process. The use of visual expression techniques for the design configurations described by these codes, which have a technical language, will help to understand the application of images created during the mental process of architectural design. Similarly, visual models help the designer in the decision-making phase, as well as in terms of their educational functions, making it easier for students to explain what they are doing (Özcan, 1994). In order to draw attention to the necessity of earthquake codes and address architects alongside engineering disciplines in order to be understood by architects in light of this information, the existing visual expressions of the given irregularity definitions are examined and the present situation evaluated. Subsequently, all the design decisions that could result in irregularity and additional stresses on a structure, and the measures taken against these irregularities, were taken into consideration. The aim being to generate an awareness for architects is achieved by simple but descriptive drawings suggested by the author.

\section{Investigation of horizontal irregularities given in different earthquake codes}

The title, horizontal irregularity, focuses upon plan configuration; namely the floor plan geometry and sizes of a building as well as its structural layout in plan. Each building requires a horizontal system that resists and then distributes inertial forces into the vertical structure (columns, shear walls) provided, in a given direction (Charleson, 2008). An irregularity in this system distorts the stability of the building (De Stefano and Pintucchi, 2008). Various factors, such as the architectural design concept, the compatibility with the site, the building programme, the desirability of introducing natural light and ventilation, and exploiting potential views cause the buildings to move away from the regular configuration (Charleson, 2008). These plan decisions, which are important in meeting the spatial requirements, are important when creating safe buildings in the design of the earthquake-resistant structure.

Horizontal irregularities may occur due to different structural causes. In this study, in the light of the extensive literature survey, torsional irregularity, diaphragms discontinuity, and geometric irregularities were examined. The geometric irregularities can be divided into four groups as re-entrant corners irregularity, dimensions ratio irregularity, nonparallel system irregularities and out of plane-offset irregularity. During the review, the importance of each title is first outlined, followed by the definitions in the codes. Later, details of visual expression for architects are revealed. 


\subsection{Torsional Irregularity}

Because of the destructive effect it creates, one of the most frequently observed types of irregularity in earthquake calculations is torsional irregularity (Özmen, 2004). The main factors affecting torsional irregularity are the planar distribution of the stiffness variation of vertical structural elements and the planar geometry of the structure. In the floor plan, it is important to keep the eccentricity between the rigidity centre and the mass centre to a minimum. In the case of eccentricity between the rigidity centre and the mass centre under the effect of the lateral forces, torsion moment occurs at the floor level. The torsional moment tends to cause additional shear forces in the columns (Döndüren et al., 2007; Özmen, 2004). The effect of these additional shear forces on columns subjected to high shear forces under earthquake loads is undesirable. The relevant definitions under the heading of torsional irregularity in the seismic codes examined in this study are given in Table 1 .

In the light of the collected data, all the seismic codes give importance to this irregularity. However, it is defined using different methods. For example;
Turkey (AFAD, 2018), China (MOHURD, 2010), India (BIS, 2002) and ASCE/SEI 7-10 (ASCE, 2016) consider the torsional irregularity according to relative displacements of the floors. In this calculation method, earthquake design criteria of the codes are used, and torsional irregularity is defined according to the dynamic behaviour of the structure. However, according to the codes of New Zealand (NZSEE, 2014), Mexico (FDGM, 1995) and Eurocode-8 (CEN, 2004), the definition of irregularity is made according to the distance between the centre of mass and rigidity. The Iranian seismic code (BHRC, 2007) defined the torsional irregularity according to the distance between the centre of mass and rigidity as well as relative floor displacements. Additionally, the New Zealand and ASCE/SEI 7-10 codes have rated this irregularity regarding structural performance based on the values obtained. From an architectural point of view, the descriptive images that offer interactive learning possibilities and increase the understanding of those studying the torsional irregularity are only found in the codes of Turkey, New Zealand and India (Fig. 2).

Table 1 Definitions of torsional irregularity in different earthquake codes.

\begin{tabular}{|c|c|}
\hline & Definitions \\
\hline TURKEY & $\begin{array}{l}\text { The case where Torsional Irregularity Factor } \eta_{b i} \text {, which is defined for any of the two orthogonal earthquake directions as the } \\
\text { ratio of the maximum storey drift at any storey to the average storey drift at the same storey in the same direction, is greater } \\
\text { than } 1.2 \text {. Storey drifts shall be calculated by considering the effects of } \pm 5 \% \text { additional eccentricities. }\end{array}$ \\
\hline CHINA & $\begin{array}{l}\text { Under the action of specified horizontal force, the maximum elastic horizontal displacement or (storey drift) of a storey is } \\
\text { larger than } 1.2 \text { times the elastic horizontal displacement (or storey drift) at both ends of this storey. }\end{array}$ \\
\hline IRAN & $\begin{array}{l}\text { In each story, the maximum drift, including accidental torsion, at one end of the structure shall not exceed } 20 \% \text { of the average } \\
\text { of the story drifts of the two ends of the structure. In each story, the distance between the centres of mass and stiffness in each } \\
\text { orthogonal direction shall not exceed } 20 \% \text { of the building dimension in that direction. }\end{array}$ \\
\hline NEW ZEALAND & $\begin{array}{c}\text { Mass to centre of rigidity offset }>0.5 \text { width (severe) } \\
\text { Mass to centre of rigidity offset }>0.3 \text { width (significant) } \\
\text { Mass to centre of } \leq 0.3 \text { width or effective torsional resistance available from elements orientated } \\
\text { perpendicularly (insignificant). }\end{array}$ \\
\hline MEXICO & At any story, the torsional eccentricity es shall not exceed 10 per cent of the in-plan dimension parallel to the eccentricity. \\
\hline INDIA & $\begin{array}{l}\text { Torsional irregularity to be considered to exist when the maximum storey drift, computed with design eccentricity, at one end } \\
\text { of the structures transverse to an axis is more than } 1.2 \text { times the average of the storey drifts at the two ends of the structure. }\end{array}$ \\
\hline EUROCODE-8 & $\begin{array}{l}\text { At each level and for each direction of analysis } x \text { and } y \text {, the structural eccentricity } e o \text { and the torsional radius } r \text { shall be in } \\
\text { accordance with the two conditions below, which are expressed for the direction of analysis } y \text { : } \\
\qquad e o x \leq 0.30 . r x ; r x \geq l s \\
\text { where; eox is the distance between the centre of stiffness and the centre of mass, measured along the } x \text { direction, which is } \\
\text { normal to the direction of analysis considered; } r x \text { is the square root of the ratio of the torsional stiffness to the lateral stiffness } \\
\text { in the } y \text {-direction; } l s \text { is the radius of gyration of the floor mass in plan }\end{array}$ \\
\hline ASCE/SEI 7-10 & $\begin{array}{l}\text { Torsional irregularity is defined to exist where the maximum story drift, computed including accidental torsion with } A x=1.0 \text {, } \\
\text { at one end of the structure transverse to an axis, is more than } 1.2 \text { times the average of the story drifts at the two ends of the } \\
\text { structure. Torsional irregularity requirements in the reference sections apply only to structures in which the diaphragms are } \\
\text { rigid or semirigid. } \\
\text { Extreme torsional irregularity is defined to exist where the maximum story drift, computed including accidental torsion with } \\
\text { Ax }=1.0 \text {, at one end of the structure transverse to an axis is more than } 1.4 \text { times the average of the story drifts at the two ends } \\
\text { of the structure. Extreme torsional irregularity requirements in the reference sections apply only to structures in which the } \\
\text { diaphragms are rigid or semirigid. }\end{array}$ \\
\hline
\end{tabular}




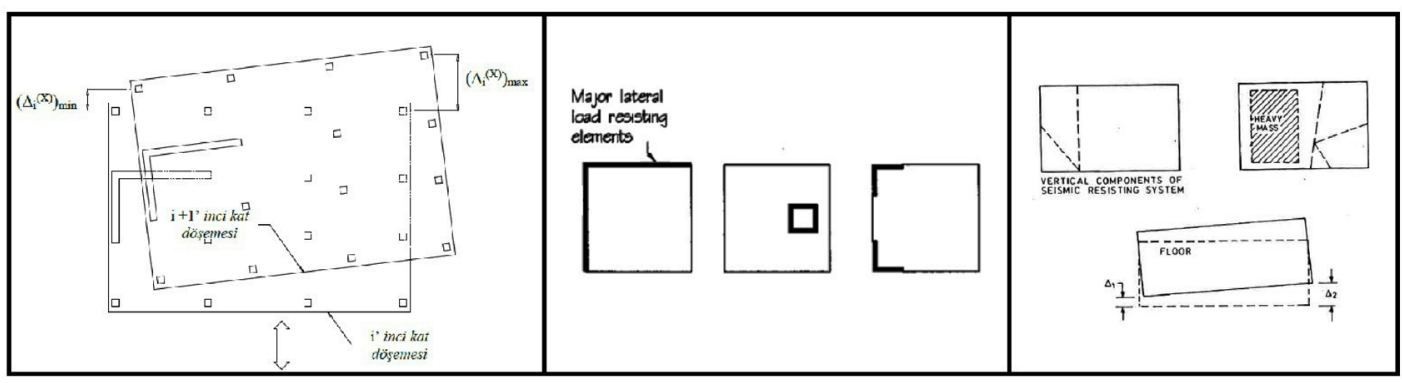

(a)

(b)

(c)

Fig. 2 Images related to torsional irregularity in the codes of (a) Turkey, (b) New Zealand and (c) India

\subsection{Diaphragms discontinuity irregularity}

The horizontal loads on the buildings are mainly concentrated at the slabs, and the horizontal loads are distributed to the vertical structural elements by the slabs. For this reason, it is necessary to transfer the inertial forces caused by the earthquake effects to the slabs and the structural system elements such as beams, columns and shear walls from the slabs (Terzi and Elçi, 2006). There are openings in slabs of varying shapes and sizes for architectural reasons such as lighting, gallery space, or mechanical reasons such as elevator bucket, installation shafts in the buildings (Öztürk, 2011). If they exceed certain ratios, these openings in the slab prevent the earthquake forces from being transmitted to the structural members, and hence cause diaphragms discontinuity irregularity. Stress concentration occurs in this case. The definitions of this irregularity, which becomes effective in the behaviour of structures under horizontal loading in the seismic codes of different countries are given in Table 2.

In the light of the examinations, in all the seismic codes, the diaphragms discontinuity was completely evaluated according to the plan geometry, and it was emphasised that an irregularity might occur resulting from the sudden stiffness change in the plan. However, limit values differ among codes. The ratio of openings in slabs is limited to $20 \%, 30 \%, 33 \%$ in the earthquake codes of Mexico (FDGM, 1995), China (MOHURD, 2010) and Turkey (AFAD, 2018) accordingly. In other codes, this ratio is limited to $50 \%$. In the New Zealand code (NZSEE, 2014) and Eurocode-8 (CEN, 2004), there is no description under the heading of this irregularity. When examining how this irregularity, which is defined with equations and texts, addresses the architects, explanatory visuals of the given irregularity were found only in the Turkish code (Fig. 3).

Table 2 Definitions of diaphragms discontinuities in different earthquake codes

\begin{tabular}{|c|c|}
\hline & Definitions \\
\hline TURKEY & $\begin{array}{l}\text { In any floor; (i) The case where the total area of the openings including those of stairs and elevator shafts exceeds } 1 / 3 \text { of } \\
\text { the gross floor area, (ii) The cases where local floor openings make it difficult the safe transfer of seismic loads to vertical } \\
\text { structural elements, (iii) The cases of abrupt reductions in the in-plane stiffness and strength of floors. }\end{array}$ \\
\hline CHINA & $\begin{array}{c}\text { The size of floor slab and the rigidity of plane change rapidly, for instance, the effective width of floor slab is less than } 50 \% \text { of } \\
\text { the typical width of floor slab at this storey, or the opening area is larger than } 30 \% \text { of the floorage of this storey or great } \\
\text { split-storey exists. }\end{array}$ \\
\hline IRAN & $\begin{array}{l}\text { Abrupt variation in diaphragm stiffness relative to the adjacent stories shall not exceed } 50 \% \text {. Moreover, the total area of } \\
\text { openings in each diaphragm shall not be greater than } 50 \% \text { of the total area of the diaphragm. }\end{array}$ \\
\hline MEXICO & $\begin{array}{l}\text { Voids in roof or floor slabs shall have dimensions smaller than } 20 \text { per cent of the plan dimension of the void considered. } \\
\text { Voids must not introduce significant asymmetry, and their position must not vary from floor to floor. The area of voids need not } \\
\text { exceed } 20 \text { per cent of the total area of the floor slab of interest. }\end{array}$ \\
\hline INDIA & $\begin{array}{l}\text { Diaphragms with abrupt discontinuities or variations in stiffness, including those having cut-out or open areas greater than } \\
50 \text { per cent of the gross enclosed diaphragm area, or changes in effective diaphragm stiffness of more than } 50 \text { per cent from one } \\
\text { storey to the next. }\end{array}$ \\
\hline ASCE/SEI 7/10 & $\begin{array}{l}\text { Diaphragm discontinuity irregularity is defined to exist where there is a diaphragm with an abrupt discontinuity or variation in } \\
\text { stiffness, including one having a cut-out or open area greater than } 50 \% \text { of the gross enclosed diaphragm area, or a change in } \\
\text { effective diaphragm stiffness of more than } 50 \% \text { from one story to the next. }\end{array}$ \\
\hline
\end{tabular}



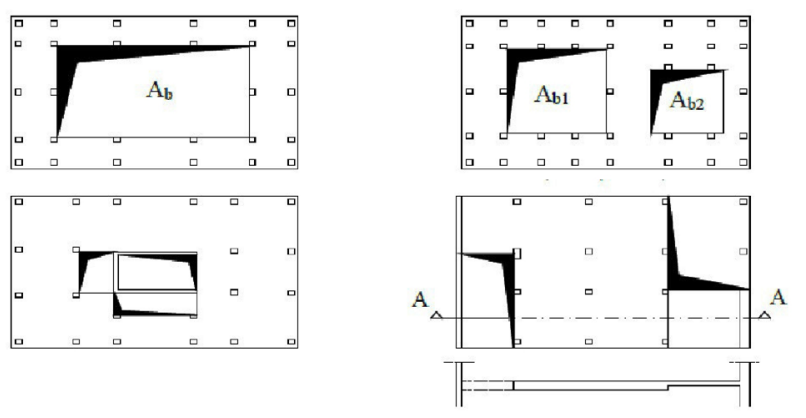

Fig. 3 Images in Turkish earthquake code related to diaphragms discontinuity

\subsection{Horizontal geometric irregularities}

The behaviour of a building during an earthquake first depends on the general shape that influences the design of the vertical structural members, geometry and size of the building. A simple arrangement of the structure allows a high earthquake resistance, and avoiding the irregularities that can occur in the plan geometry during the design phase is crucial regarding structural behaviour (Ahmed et al., 2016).

Structural behaviours of buildings with irregular geometry in plan can be negatively affected due to the following reasons: time-dependent deformation such as temperature difference, creep and shrinkage, different settlements, and different reactions to dynamic forces. Thus, some load-bearing system elements may be exposed to excessive stresses. In this study, geometrical irregularities in the plan, which are physically different from each other in behaviour and physics are re-entrant corners irregularity, dimensions ratio irregularity, non-parallel system irregularity, and out of plane offset irregularity.

\subsubsection{Re-entrant corner irregularity}

In architectural planning, setbacks on the facade, sections or parts placed at different angles, different plan solutions compared to basic geometries to adapt to the land are common design choices. The shape of H, L, T, U, Y, cross, or a combination of these forms are the typical examples of building configuration which have projections or wings in plan constituting re-entrant corners (Mendi, 2005). The building corners formed inwards, or outwards are one of the most common applications of geometric irregularities. These applications are subject to energy concentrations under the dynamic earthquake effects, resulting in severe stress concentration in the corners. Table 3 contains the definitions of the codes for the presence of the projections. Definitions of irregularities for the presence of re-entrant corners in the studied codes were generally made based on the dimensions in the plan geometry, but the limit values differ.

Table 3 Definitions of re-entrant corners irregularity in the plan in different earthquake codes

\begin{tabular}{|c|c|}
\hline & Definitions \\
\hline TURKEY & $\begin{array}{l}\text { The cases where projections beyond the re-entrant corners in both of the two principal directions in plan exceed the total plan } \\
\text { dimensions of the building in the respective directions by more than } 20 \% \text {. }\end{array}$ \\
\hline CHINA & The sunken size of plane is larger than $30 \%$ of the overall size in the corresponding projection direction. \\
\hline IRAN & $\begin{array}{l}\text { In case there is any setback or projection, their dimension in each direction shall not exceed } 25 \% \text { of the respective building } \\
\text { dimension in that direction. }\end{array}$ \\
\hline $\begin{array}{l}\text { NEW } \\
\text { ZEALAND }\end{array}$ & $\begin{array}{c}\text { L-shape, T-shape, E-shape; } \\
\text { Two or more wings length / width }>3.0 \text {, or one wing length } / \text { width }>4 \text { (severe) } \\
\text { One wing length } / \text { width }>3.0 \text { (significant) } \\
\text { All wings length / width } \leq 3.0 \text { (insignificant) }\end{array}$ \\
\hline MEXICO & $\begin{array}{l}\text { The plan shall not have protruding or re-entrant portions with dimensions larger than } 20 \text { per cent of the plan dimension } \\
\text { measured parallel to the direction of the protruding portion or re-entrance considered. }\end{array}$ \\
\hline INDIA & $\begin{array}{l}\text { Plan configurations of a structure and its lateral force resisting system contain re-entrant corners. Where both projections of the } \\
\text { structure beyond the re-entrant corner are greater than } 15 \text { per cent of its plan dimension in the given direction. }\end{array}$ \\
\hline EUROCODE-8 & $\begin{array}{l}\text { If in plan set-backs (re-entrant corners or edge recesses) exists, regularity in plan may still be considered as being satisfied, } \\
\text { provided that these set-backs do not affect the floor in-plan stiffness and that, for each set-back, the area between the outline of } \\
\text { the floor and convex polygonal line enveloping the floor does not exceed } 5 \% \text { of the floor area. } \\
\text { The in-plan stiffness of the floors shall be sufficiently large in comparison with the lateral stiffness of the vertical structural } \\
\text { elements so that the deformation of the floor shall have a small effect on the distribution of the forces among the vertical } \\
\text { structural elements. In this respect, the L, C, H, I, and X plan shapes should be carefully examined, notably as concerns the } \\
\text { stiffness of the lateral branches, which should be comparable to that of the central part, in order to satisfy the rigid diaphragm } \\
\text { condition. The application of this paragraph should be considered for the global behaviour of the building. }\end{array}$ \\
\hline ASCE/SEI 7/10 & $\begin{array}{l}\text { Re-entrant corner irregularity is defined to exist where both plan projections of the structure beyond a re-entrant corner are } \\
\text { greater than } 15 \% \text { of the plan dimension of the structure in the given direction. }\end{array}$ \\
\hline
\end{tabular}


Limit values of the ratios of the re-entrant corner width to the plan width are $30 \%, 25 \%, 20 \%$, and $15 \%$, in China (MOHURD, 2010), Iran (BHRC, 2007), Turkey (AFAD, 2018), Mexico (FDGM, 1995), India (BIS, 2002) and ASCE (ASCE, 2016), respectively. In Eurocode-8 (CEN, 2004), this irregularity is expressed by the area value and the limit is $5 \%$. Also, $\mathrm{L}, \mathrm{C}, \mathrm{H}, \mathrm{I}$, and $\mathrm{X}$ plan shaped buildings need more careful examination regarding the general behaviour of the building because of the presence of the wings. The New Zealand Code (NZSEE, 2014) has devised a detailed description of this irregularity under the heading of composite geometry and defined it using the ratio of the plan dimensions. When examined regarding the components that will help in visualising the definitions, only Turkey, India, and New Zealand codes contain descriptive images (Fig. 4).

\subsubsection{Dimensions ratio irregularity}

If the dimensions of the structures are close to each other, the structure exhibits a stable behaviour under the influence of horizontal loads. Increasing the difference between the dimensions increases the slenderness in the plan, and the effect of the slenderness in the plan creates different behaviours in the structure due to vibration, heat, shrinkage and different settlements. Table 4 shows the definitions of the dimensions ratio irregularity in various seismic codes.

Under the irregularity heading, only three of the examined codes contain definitions based on the plan geometry, but the limit values differed in these codes. According to the Mexican seismic code (FDGM, 1995) and Eurocode-8 (CEN, 2004), the limit of the slenderness ratio is 2.5 and 4 , respectively. In the New Zealand code (NZSEE, 2014), this irregularity is examined according to the ratio of the structural system axis spacing to the building width at different ranges of values in detail. None of the codes contain explanatory visuals that increase the level of perception and provide interactive learning opportunities for architects.
Table 4 Definitions of dimensions ratio irregularity in different earthquake codes

\begin{tabular}{|c|c|}
\hline & Definitions \\
\hline $\begin{array}{l}\text { NEW } \\
\text { ZEALAND }\end{array}$ & $\begin{array}{l}\text { Long narrow building where spacing of lateral } \\
\text { load resisting elements is ... } \\
>4 \text { times building width (severe) } \\
>2 \text { times building width (significant) } \\
\leq 2.0 \text { times building width (insignificant) }\end{array}$ \\
\hline MEXICO & The ratio of length to width must be less than 2.5. \\
\hline EUROCODE-8 & $\begin{array}{l}\text { The slenderness } \lambda=L \max / L \min \text { of the building } \\
\text { in plan shall be not higher than } 4 \text {, where } L \max \\
\text { and } L \text { min are respectively the larger and smaller } \\
\text { in plan dimension of the building, measured in } \\
\text { orthogonal directions. }\end{array}$ \\
\hline
\end{tabular}

\subsubsection{Non-parallel system irregularity}

The symmetry of structures is important in the concept of structural engineering. Non-parallel system irregularity exists if the vertical lateral force-retaining elements are neither parallel nor symmetric with main orthogonal axes of the earthquake-retaining axis system (Teddy et al., 2017). This type of irregularity is commonly seen as a result of the street intersections or requirements of the space organisation in design. Architects generally begin planning according to the parcel form. Their main goal for doing this is to take advantage of the maximum parcel area in line with owner requirements (İnan and Korkmaz, 2011). This irregularity, generated by these requirements that are very difficult to change during design, causes the buildings to experience torsion or local stresses concentrations. Table 5 contains definitions of the non-parallel system irregularities in the seismic codes. The codes should comprise directions regarding this irregularity to designers creating awareness of the earthquake behaviour of buildings.

Definitions of the non-parallel system irregularities are addressed in the seismic codes of China (MOHURD, 2010), Iran (BHRC, 2007), Mexico (FDGM, 1995), ASCE/SEI 7/10 (ASCE, 2016) and India (BIS, 2002). In general, it has been mentioned that the vertical structural elements being parallel or symmetrical with respect to two orthogonal axes. However, no limitation is made on this

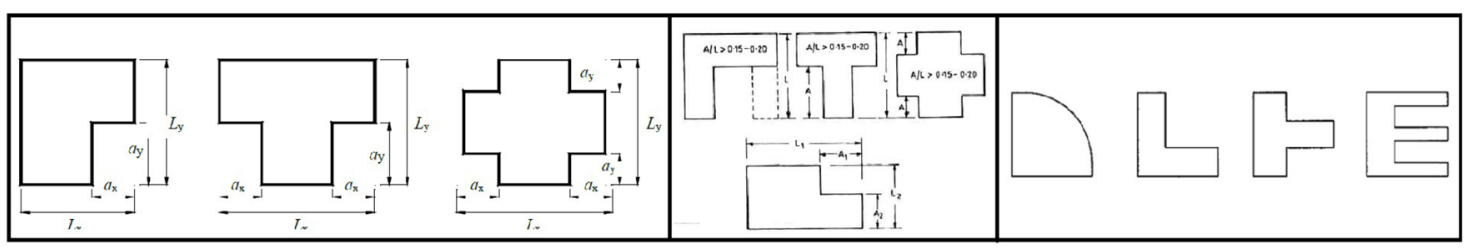

(a)

(b)

(c)

Fig. 4 Images related re-entrant corner irregularity in the codes of (a) Turkey, (b) India and (c) New Zealand 
Table 5 Definitions of non-parallel system irregularity situation in different codes and standards

\begin{tabular}{lc}
\hline CHINA & $\begin{array}{c}\text { Definitions } \\
\text { The plan layout of its lateral-force-resisting component } \\
\text { should be regular and symmetric. }\end{array}$ \\
\hline IRAN & $\begin{array}{c}\text { The plan of the building shall be symmetric or almost } \\
\text { symmetric about its principal axes, where the lateral } \\
\text { load resisting elements are generally aligned. }\end{array}$ \\
\hline MEXICO & $\begin{array}{c}\text { The plan must be nearly symmetric with respect to two } \\
\text { orthogonal axes. This condition applies to masses as } \\
\text { well as all kinds of resisting elements. }\end{array}$ \\
\hline INDIA & $\begin{array}{c}\text { The vertical elements resisting the lateral force are not } \\
\text { parallel to or symmetric about the major orthogonal } \\
\text { axes or the lateral force resisting elements. }\end{array}$ \\
\hline 7/10 & $\begin{array}{c}\text { Nonparallel system irregularity is defined to exist } \\
\text { where vertical lateral force-resisting elements are not } \\
\text { parallel to the major orthogonal axes of the seismic- } \\
\text { force-resisting system. }\end{array}$ \\
\hline
\end{tabular}

subject. The other codes do not mention the definition of non-parallel system irregularity. In addition, no visuals that will aid in perception by visualising the context have been used in any of the codes.

\subsubsection{Out of plane-offset irregularity}

The placement of the structural elements on the axes and the continuation of these axes along the height of the building is an important criterion for the rational structure behaviour. Unlike the vertical member discontinuity irregularity of the structural system, out of plane-offset irregularity refers to the fact that the vertical members bearing horizontal force are located on another axis rather than its own axis continuing along the height of the structure. Divergence from the axis causes the building to shift its centre of rigidity in a certain direction. Also, the displaced floor resulting from the movement on the boundary axis creates a stiffness gradient between the bottom and upper floors. Table 6 lists the definitions of different countries' seismic codes dealing with this irregularity that cause excessive stresses during the transmission of horizontal forces.

In the light of the collected data, this irregularity has only been addressed in the ASCE/SEI 7-10 (ASCE, 2016) and the Indian (BIS, 2002) codes. In these codes, it has been mentioned that if the vertical structural elements are out of plane, this irregularity will occur, no limit values have been given. Also, these codes do not include explanatory images on this irregularity.

\section{Discussion}

Plan designs that resist the lateral forces and determine the load distribution are important to ensure that the structure is
Table 6 Definitions of out of plane offset irregularity in different standards and codes

\begin{tabular}{lc}
\hline INDIA & $\begin{array}{c}\text { Discontinuities in a lateral force resistance path, such } \\
\text { as out-of-plane offsets of vertical elements. }\end{array}$ \\
\hline $\begin{array}{l}\text { ASCE/SEI } \\
7 / 10\end{array}$ & $\begin{array}{c}\text { Out-of-plane offset irregularity is defined to } \\
\text { exist where there is a discontinuity in a lateral } \\
\text { force-resistance path, such as an out-of-plane offset } \\
\text { of at least one of the vertical elements. }\end{array}$ \\
\hline
\end{tabular}

safe against earthquake. For this reason, detailed definitions of irregularities in the plan are included in the earthquake codes of the countries. It is considered that the criteria for structural irregularities in most of the earthquake codes are similar. However, depending on the seismic history of the regions, the economic situation of the countries, and their attitudes towards earthquake-resistant structure design, each country has different restrictions under different sub-headings. In this study, codes of the countries of different seismic experiences; India (BIS, 2002), Mexico (FDGM, 1995), New Zealand (NZSEE, 2014), Iran (BHRC, 2007), China (MOHURD, 2010) and Turkey (AFAD, 2018), and earthquake codes of the European Union countries located on active fault lines (Eurocode-8 (CEN, 2004)) and ASCE/ SEI 7-10 (ASCE, 2016) have been examined in detail. In Table 7, all irregularities that can occur resulting from design decisions on the plan level are categorised for the examined seismic codes. In addition, it was also assessed in this table that if the examined codes were supported by explanatory visuals, it would help architects.

These design decisions, which will create irregularity, are considered, and the precautions that can be taken against horizontal irregularities are explained as follows in order to create awareness for architects. Also, because of the better comprehension of visual forms in human perception, the subject is illuminated with simple but descriptive drawings:

- Torsional irregularity is mentioned in all codes, and calculation methods are given in detail. In addition to the detailed technical explanations given in Table 1, the illustrations and graphics that are helpful for understanding are only used in the three codes. In case of eccentricity between the centre of rigidity and centre of mass under the effect of horizontal forces (Fig. 5a), the most basic solution to avoid this disorder, which creates a torsional moment at the floor level, is to approach or match the centre of mass and the centre of rigidity. It is very difficult to alter the centre of mass of a structure. However, by modifying the location of the structural elements 
Table 7 Presence of conditions related to irregularities in the plan and explanatory visuals

\begin{tabular}{|c|c|c|c|c|c|c|c|c|c|}
\hline & & TURKEY & CHINA & IRAN & $\begin{array}{c}\text { NEW } \\
\text { ZEALAND }\end{array}$ & MEXICO & INDIA & EUROCODE-8 & $\begin{array}{c}\text { ASCE/SEI } \\
7-10\end{array}$ \\
\hline \multicolumn{2}{|c|}{ Torsional irregularity } & $\sqrt{ }$ & $\sqrt{ }$ & $\sqrt{ }$ & $\sqrt{ }$ & $\sqrt{ }$ & $\sqrt{ }$ & $\sqrt{ }$ & $\sqrt{ }$ \\
\hline \multicolumn{2}{|c|}{ Diaphragms discontinuity } & $\sqrt{ }$ & $\sqrt{ }$ & $\sqrt{ }$ & - & $\sqrt{ }$ & $\sqrt{ }$ & - & $\sqrt{ }$ \\
\hline \multirow{4}{*}{$\begin{array}{l}\text { Geometrical } \\
\text { irregularity }\end{array}$} & Re-entrant corners & $\sqrt{ }$ & $\sqrt{ }$ & $\sqrt{ }$ & $\sqrt{ }$ & $\sqrt{ }$ & $\sqrt{ }$ & $\sqrt{ }$ & $\sqrt{ }$ \\
\hline & $\begin{array}{l}\text { Dimensions ratio } \\
\text { irregularity }\end{array}$ & - & - & - & $\sqrt{ }$ & $\sqrt{ }$ & - & $\sqrt{ }$ & - \\
\hline & $\begin{array}{l}\text { Non-parallel system } \\
\text { irregularity }\end{array}$ & - & $\sqrt{ }$ & $\sqrt{ }$ & - & $\sqrt{ }$ & $\sqrt{ }$ & - & $\sqrt{ }$ \\
\hline & $\begin{array}{l}\text { Out of plane offset } \\
\text { irregularity }\end{array}$ & - & - & - & - & - & $\sqrt{ }$ & - & $\sqrt{ }$ \\
\hline
\end{tabular}

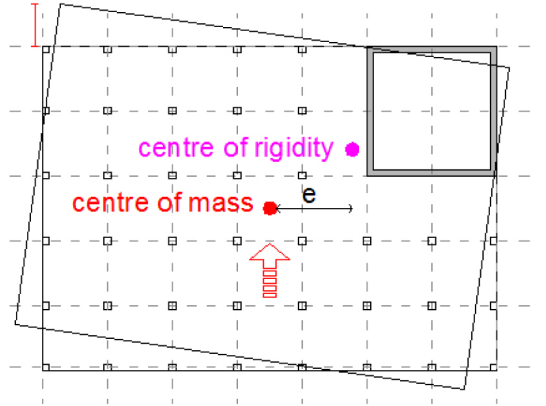

(a)

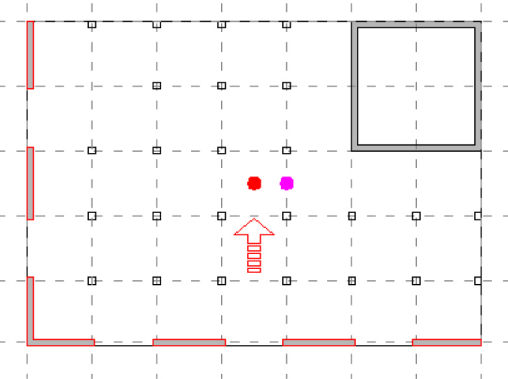

(b)

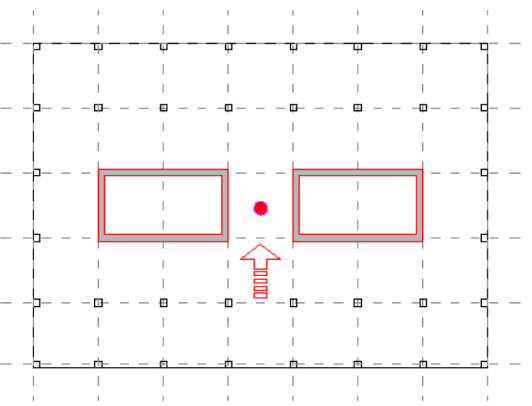

(c)

Fig. 5 Explanatory figures for torsional irregularity suggested in this study

or their cross-sections, the centre of rigidity can be changed. Instead of a small number of large shear walls, a large number of smaller shear walls is preferred (Fig. 5b). Using a small number of large shear walls is always dangerous as any shear wall damage can cause the building to collapse. Choosing a large number of small shear walls that can do the same tasks as the small number of large shear walls will reduce the risk of collapse. It is also an ideal solution to make the geometry of the plan simple and to place the vertical structural elements symmetrically in every direction (Fig. 5c). In this study, it is suggested that it will be easier to understand this irregularity with the drawings similar to that given in Fig. 5.

- Diaphragms discontinuity irregularity is the most often emphasised title of irregularities among the eight codes. However, this irregularity does not exist in New Zealand seismic code (NZSEE, 2014) and Eurocode-8 (CEN, 2004). The visual presentation that will provide an effective way of understanding this irregularity by architects was found only in Turkish codes (AFAD, 2018). However, with the drawings as in Fig. 6, more understandable information transfer will be provided. Damage to the
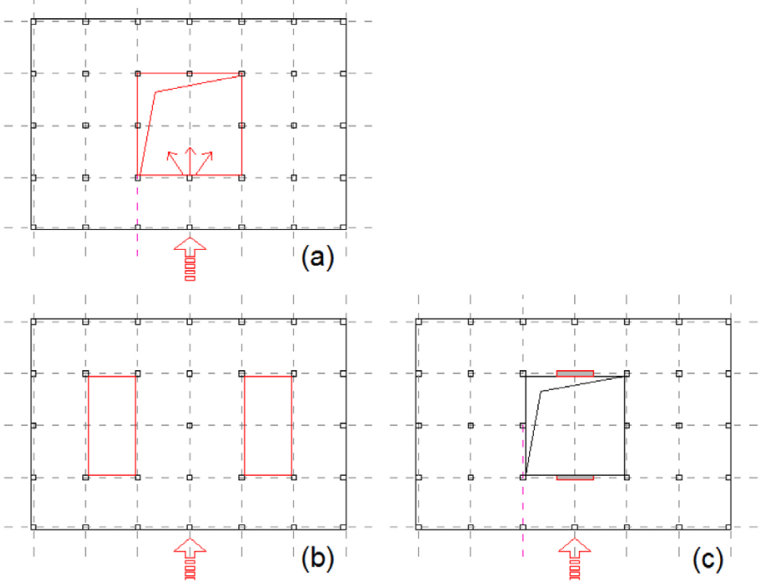

Fig. 6 Explanatory figures for diaphragms discontinuity irregularity suggested in this study

columns and beams will be inevitable because the beams that are discontinuous will move in different directions due to the earthquake forces (Fig. 6a), since the operation of the slab, as a whole, will be significantly affected by the openings in the slab. Also, that the slab does not work as a rigid diaphragm due to the presence of openings, has a large effect on the torsional irregularity. 
During an earthquake, it is desirable that the openings in the slabs be as small, symmetrical, and even as possible so as not to adversely affect the behaviour of the building (Fig. 6b). If there is no important reason, continuing only the boundary beam along the opening shows better behaviour than that of the discontinuous beam. If this is not the case, the rigidity of the columns and beams around the openings should be increased, or shear walls should be placed around the openings to prevent any differences between the slabs (Fig. 6c).

- The situation of re-entrant corners, referred to in all earthquake codes, is an important decision in the design of the building form and has a fundamental effect on the behaviour of the building. Drawings and graphics are used in only three seismic codes, which make it easier for architects to understand the subject. However, with the drawings as in Fig. 7, more understandable information transfer will be provided. The buildings having projections (or wings) have often been severely damaged in earthquakes. The negative effects of this irregularity can be summed up in two parts. Firstly, at the corner points where the notches are joined, stress concentration occurs due to different stiffnesses and different movements of these parts of the building (Fig. 7a-b). The second effect is torsional forces, which tend to distort the form and are very difficult to analyse and predict. It is not possible for the centre of mass and the rigidity centre to match each other geometrically for all possible earthquake directions in buildings having re-entrant corners (Arnold et al., 2001).

The solutions for re-entrant corners in the buildings are as follows: (i) using dilatations in a structurally meaningful manner to obtain completely separate and regular forms (Fig. 7c), (ii) using vertical structural elements to provide stiffness to the structure in response to torsional and separation behaviour of the corners (Fig. 7d), (iii) providing significantly smoother transitions rather than right angles at the corners (Fig. 7e) (Arnold et al., 2001; Mendi, 2005).

- Dimensions ratio irregularity is an important consideration for seismic performance of a building. As the ratio of a dimension length to its width in plan increases, a building may experience problems in responding to the dynamic ground movements as a whole, even if it is symmetrical and simple (Fig. 8a) (Arnold et al., 2001). This is because earthquakes are likely to have
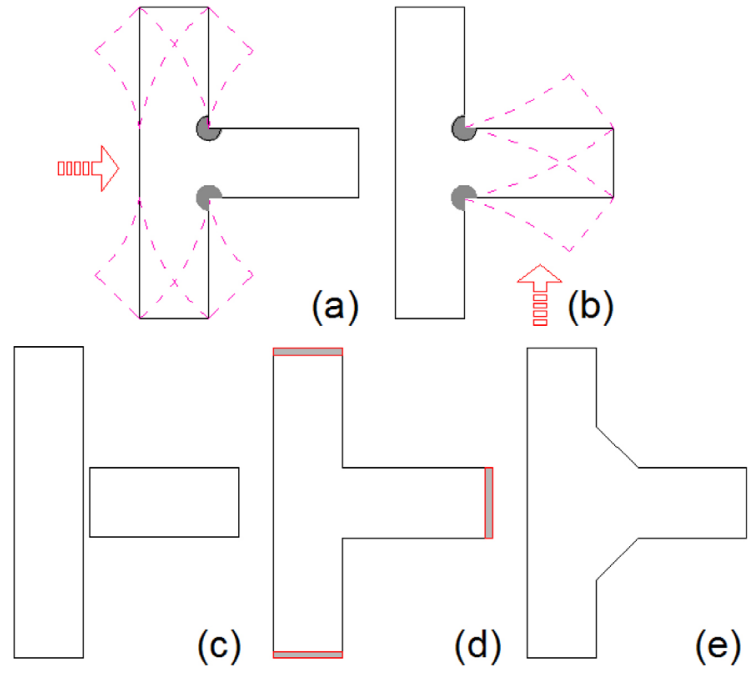

Fig. 7 Explanatory figures for re-entrant irregularity suggested in the study
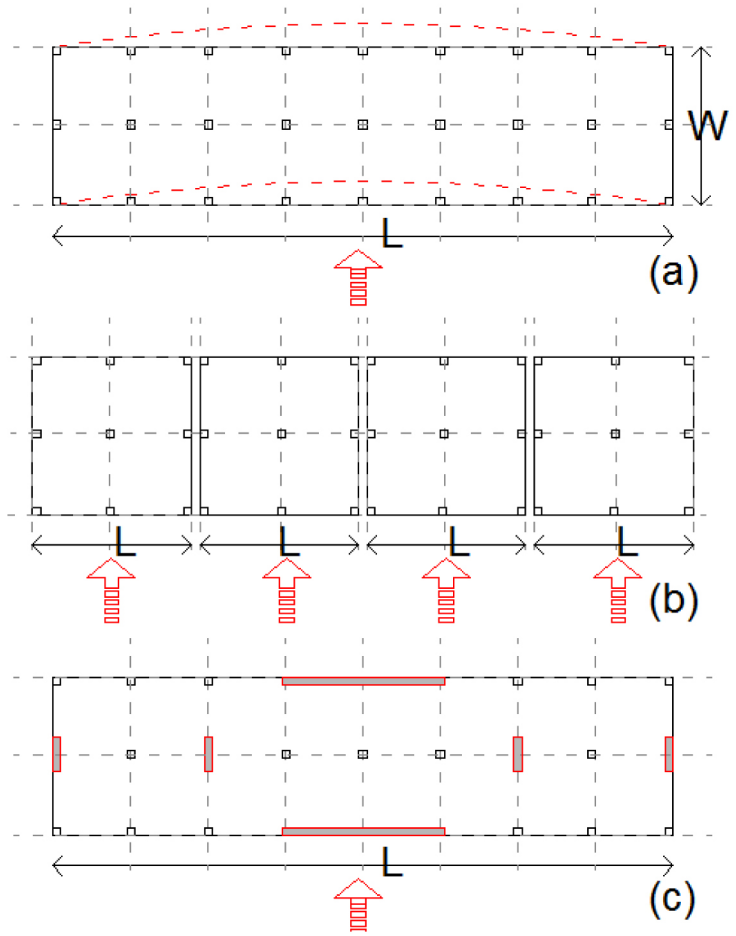

Fig. 8 Explanatory figures for dimensions ratio irregularity suggested in this study

different ground movements, and structures may exhibit different behaviour along their lengths. Furthermore, due to differences in geological conditions, different displacements and different stresses can be experienced (Dowrick, 1987). Only three of the eight seismically active countries' codes (New Zealand (NZSEE, 2014), Mexico (FDGM, 1995) 
and Eurocode-8 (CEN, 2004)) have directions on the dimensions ratio irregularity, but this is not supported by visuals. However, it has been revealed in a study by İlerisoy and Tuna (2018b) that the structures containing simple geometric dimensional differences in the plane of the plan will cause a change in the structural system calculations and hence the cost values in different orders, even though they do not result in significant architectural differences.

The measures to be taken in order to improve seismic behaviour when such a long building is required as a design requirement can be listed as follows; (i) with dilatation joints, the building can be divided into shorter, more compact, independent forms (Fig. 8b), (ii) addition of vertical structural system elements (shear walls and columns) that will not adversely affect a building's resistance to torsion, and will exhibit more resistant stiffness to lateral forces (Fig. 8c), (iii) using the more rigid foundation types, the adverse effects can be essentially damped (Dowrick, 1987).

- The non-parallel system irregularity resulting from the fact that the axes of the structures are not perpendicular or parallel to each other is mentioned in the seismic codes of China (MOHURD, 2010), Iran (BHRC, 2007), Mexico (FDGM, 1995), India (BIS, 2002) and ASCE/SEI 7-10 (ASCE, 2016), but it is not supported by visual expression techniques. Care should be taken to place the vertical structural elements in a parallel axis system that is perpendicular to each other or at least similar to each other. Randomly placed axes will interfere with the rational transfer of loads between the columns and beams to one another, and thus the seismic performance of the structure will be reduced (Fig. 9a). Moreover, this difference will increase the risk of torsion as it prevents the centre of mass and rigidity from overlapping.

In this case, the building should be separated into simple and regular forms with seismic joints in order to reduce the effects of torsion (Fig. 9b) (Mendi, 2005) or torsion should be prevented by adding strong vertical elements to the axis, which weakens this system (Fig. 9c).

- Out of plane offset irregularity, mentioned only in India seismic code (BIS, 2002) and ASCE/SEI 7-10 (ASCE, 2016), occurs where there is a disconnection of the horizontal forces transferred to the foundation by the structural system. Unfavourable stress concentrations, stiffness change between floors, and even torsional effects will be experienced in the floors where there is a discontinuity in the flow of the lateral forces to the foundation (Fig. 10). The most important way of avoiding this irregularity, which has a similar effect to vertical structural elements discontinuity irregularity, is not to change axes of column and shear walls.

All these important design precautions are explained with simple but descriptive drawings. If a similar way is followed in the codes, explanation of these irregularities, both text and visuals, will help architects apply these directions more easily in practice.
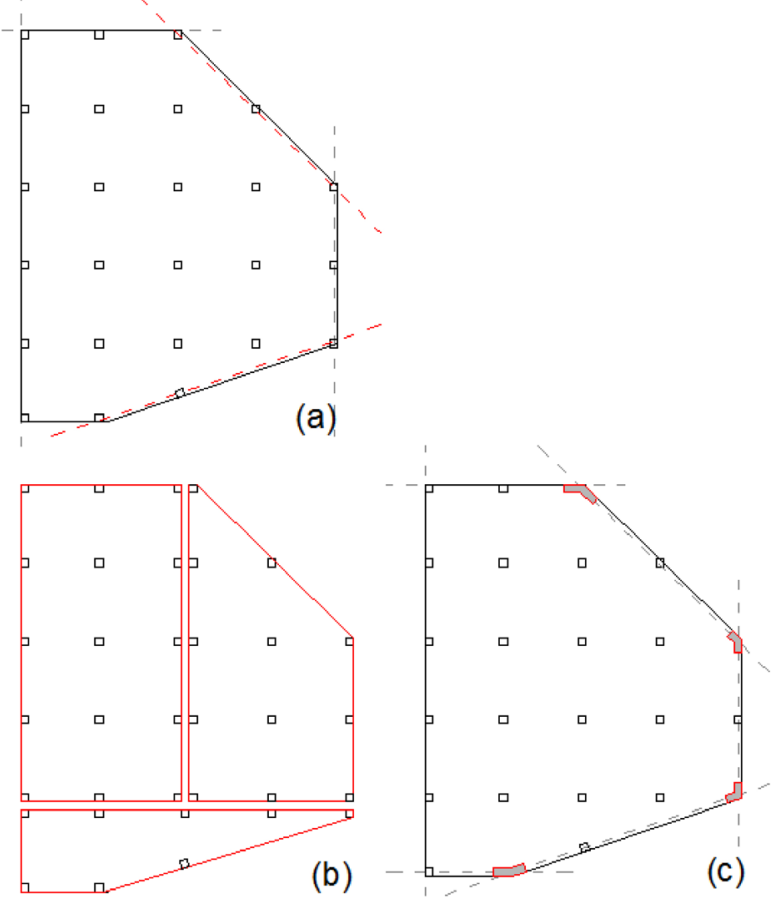

Fig. 9 Explanatory figures for non-parallel system irregularity suggested in this study

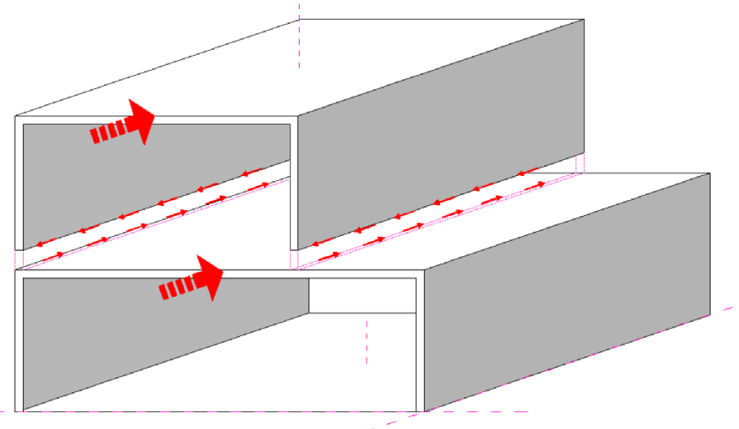

Fig. 10 Explanatory figures for out of plane offset irregularity suggested in this study 


\section{Conclusion}

When the causes of damage resulting from earthquakes are examined, the failure of a structure under earthquake loads usually begins in the architectural design process. Decisions regarding the configuration of the structural system, which is the most important step in the design of the earthquake-resistant structure, are taken in the architectural design phase. Similarly, it is emphasised in the literature that the stage that has the highest chance of affecting the building cost is this design phase. In order to be able to implement a structure in an ideal way, it is necessary to avoid the situations that are not very necessary and affect the costs negatively in the projects. Structural irregularities in buildings located in earthquake zones should be discussed regarding cost reduction. As a result, the more regular the system becomes, the more rational behaviour of the building under the effects of earthquake. The strength of construction is increased against these dynamic loads, and more economical applications are obtained compared to irregular buildings.

Earthquake codes bring various requirements, with the more sensitive calculations for the buildings having irregularities in their structural system. Although some of the irregularities can be eliminated during the dimensioning of the structural elements' sections, they are not economical, and some cannot be eliminated. The negative effects of irregularities in the structures can only be avoided in the architectural design phase; once the design is complete, it becomes increasingly difficult to prevent them during the construction stage.

In this study, which examines how design decisions in plan level are addressed in existing earthquake codes, the aim has been to create awareness in the context of the handling of this subject by architects in terms of designing regular structure regarding geometry and stiffness distribution. For this purpose, eight different seismic codes

\section{References}

AFAD (Prime Ministry Disaster and Emergency Management Authority) (2018) "Turkish Building Earthquake Code (TDBY2018)", Prime Ministry Disaster and Emergency Management Authority, Ankara, Tukey.

Ahmed, M. M. M., Raheem, S. E. A., Ahmed, M. M., Abdel-Shafy, A. G. A. (2016) "Irregularity Effects on the Seismic Performance of L-Shaped Multi-Story Buildings", Journal of Engineering Science Assiut University Faculty of Engineering, 44(5), pp. 513536. [online] Available at: http://www.aun.edu.eg/journal_ files/504_J_6 621.pdf [Accessed: 15 August 2018] of the countries located on active fault lines and having different seismic histories were compared and the results evaluated regarding the irregularities in the plan. First, the literature survey yielded a total of six criteria, which would result in irregularity in plan. Three of these criteria are defined and explained in the seismic codes of Turkey (AFAD, 2018), New Zealand (NZSEE, 2014) and Eurocode-8 (CEN, 2004); while four are defined for China (MOHURD, 2010) and Iran (BHRC, 2007) and five for Mexico (FDGM, 1995), India (BIS, 2002) codes and the ASCE/SEI 7-10 (ASCE, 2016). However, the seismic codes are lacking connection with architects. At this point, all responsibility is given to the civil engineer. This leads to a fragmentary approach rather than being integral to building production. It has been observed that there are no drawings for the designs proposed in the earthquake codes of China, Iran, Mexico, Eurocode 8 and ASCE/SEI 7-10 regarding the auxiliary visuals; this is a necessary tool especially for the codes to act as guidelines for architectural disciplines. However, the earthquake acts as a whole to the building and does not distinguish between the elements designed by the architect or the engineer. Turkey, New Zealand and India seismic codes include visuals, and it has been observed that even the drawings are in similar subjects. These three codes contain images regarding torsional irregularity and the presence of re-entrant corners irregularity. In addition to these, the Turkish code includes visuals of diaphragms discontinuity. This study, which comprehensively discusses the situations that are expected to create horizontal irregularities, provides detailed descriptions of the visual expressions and recommends some solutions for these irregularities. In conclusion, this study can be considered as a source for understanding earthquake codes, revealing information about architecture in the face of the ever-changing reality of earthquake, and giving architects the tools that they can use effectively in this regard.

Alden, A. (2017) "The World's Major Earthquake Zones", [online] Available at: https://www.thoughtco.com/seismic-hazard-mapsof-the-world-1441205 [Accessed: 20 August 2018]

Allen, R. M. (2007) "4.21 - Earthquake Hazard Mitigation: New Direction and Opportunities", Treatise on Geophysics, 4, pp. 607-647. https://doi.org/10.1016/B978-044452748-6/00083-3

Ankara Chamber of Architects (2007) "Sürekli Mesleki Gelişim Merkezi Öneri Eğitim Programları", (Continuing Professional Development Centre Suggestion Training Programs) [online] Available at: www. mimarlarodasiankara.org/dosya/SMGM-kitap.doc [Accessed: 20 August 2018] (in Turkish) 
Arnold, C., FAIA, RIBA (2001) "Architectural Considerations", In: Naeim, F. (ed.) The Seismic Design Handbook, 2nd ed., Springer, Boston, MA, USA, pp. 275-326. https://doi.org/10.1007/978-1-4615-1693-4_6

ASCE (American Society of Civil Engineers) (2016) "Minimum Design Loads for Buildings and Other Structures (ASCE Standard ASCE/ SEI 7-10)", American Society of Civil Engineers, Reston, USA.

BHRC (Building and Housing Research Center) (2007) "Iranian Code of Practice for Seismic Resistant Design of Buildings (Standard No. 2800)", Building and Housing Research Center, Tehran, Iran.

BIS (Bureau of Indian Standards) (2002) "Indian Standard Criteria for Earthquake Resistant Design of Structures (IS 1893Part 1)", Government of India, Ministry of Earth Sciences, New Delhi, India.

CEN (European Committee for Standardization) (2004) "Eurocode 8: Design of Structures for Earthquake Resistance - Part 1: General Rules, Seismic Actions and Rules for Buildings (BS EN 1998-1:2004)", European Committee for Standardization, Brussels, Belgium.

Charleson, A. (2008) "Seismic Design for Architects: Outwitting the Quake", 1st ed., Architectural Press, Oxford, UK.

De Stefano, M., Pintucchi, B. (2008) "A review of research on seismic behaviour of irregular building structures since 2002", Bulletin of Earthquake Engineering, 6(2), pp. 285-308. https://doi.org/10.1007/s10518-007-9052-3

Dowrick, D. J. (1987) "Earthquake Resistant Design: For Engineers and Architects", 2nd ed., John Wiley \& Sons, Chichester, USA.

Döndüren, M. S., Karaduman, A., Çöğürcü, M. T., Altın, M. (2007) "Yapılarda burulma düzensizliği", (Torsional Irregularity in the Structures) Journal of Selcuk-Technic, 6(1), pp. 42-52. [online] Available at: http://sutod.selcuk.edu.tr/sutod/article/view/35/576 [Accessed: 15 August 2018] (in Turkish)

FDGM (Federal District Government of Mexico) (1995) "Mexico City Building Code: Complementary Technical Norms for Earthquake Resistant Design", [online] Available at: http://iisee.kenken.go.jp/ worldlist/Web/33_Mexico.htm [Accessed: 21 August 2018]

Harmankaya, Z. Y., Soyluk, A. (2012) "Architectural Design of Irregular Buildings in Turkey", International Journal of Civil \& Environmental Engineering (IJCEE-IJENS), 12(01), pp. 42-48. [online] Available at: http://ijens.org/Vol_12_I_01/125001-9494IJCEE-IJENS.pdf [Accessed: 15 August 2018]

IAEE (International Association for Earthquake Engineering) "Regulations for Seismic Design - A World List (2016)", [online] Available at: http://www.iaee.or.jp/worldlist.html [Accessed: 20 August 2018]

İlerisoy, Z. Y., Tuna, M. E. (2018a) "Effects of Height and Plan Geometry on the Costs of Tunnel Form Residential Buildings", Periodica Polytechnica Architecture, 49(1), pp. 29-37.

https://doi.org/10.3311/PPar.12384

İlerisoy, Z. Y., Tuna, M. E. (2018b) "Dikdörtgen Planlı Tünel Kalıp Kullanılan Betonarme Yapılarda Plan Boyutları ve Kat Adedinin Maliyete Etkileri", (Effects of Plane Dimensions and Number of Storeys On the Cost of Rectangular-Plane Buildings Constructed with Tunnel Form) Megaron, 13(4), pp. 559-568. (in Turkish) https://doi.org/10.5505/megaron.2018.98698

İnan, T., Korkmaz, K. (2011) "Evaluation of structural irregularities based on architectural design considerations in Turkey", Structural Survey, 29(4), pp. 303-319.

https://doi.org/10.1108/02630801111162378
Maver, T. W. (1970) "A Theory of Architectural Design in which the Role of the Computer is Identified", Building Science, 4(4), pp. 199-207. https://doi.org/10.1016/0007-3628(70)90022-8

Mendi, H. E. (2005) "Evaluation of Architectural Consciousness and Exploration of Architecture-Based Issues in Seismic Design", MSc Thesis, Middle East Technical University, Ankara, Turkey.

MOHURD (Ministry of Housing and Urban-Rural Development of the People's Republic of China) (2010) "Code for Seismic Design of Buildings (GB 50011-2010)", Ministry of Housing and Urban-Rural Development of the People's Republic of China, Beijing, China.

NZSEE (New Zealand Society for Earthquake Engineering) (2007) "Architectural Design for Earthquake: A guide to the design of non-structural elements", [online] Available at: https://www.nzsee. org.nz/db/PUBS/ADE2007.pdf [Accessed: 21 August 2018]

NZSEE (New Zealand Society for Earthquake Engineering) (2014) "Assessment and Improvement of the Structural Performance of Buildings in Earthquakes", [online] Available at: https:// www.nzsee.org.nz/db/PUBS/2006AISBEGUIDELINESCorr3 (incl_2014_updates).pdf [Accessed: 21 August 2018]

Özcan, O. (1994) "Mimari Tasarım Acısından Bilgisayar Modeli, Maketin Yerini Alabilir mi?", (Can the Computer Model Replace Real Models in terms of Architectural Design?) CAD+, 12, pp. 34-37. (in Turkish)

Özmen, C., Ünay, A. İ. (2007) "Commonly Encountered Seismic Design Faults due to the Architectural Design of Residential Buildings in Turkey", Building and Environment, 42(3), pp. 1406-1416. https://doi.org/10.1016/j.buildenv.2005.09.029

Özmen, C. (2008) "A Comparative Structural and Architectural Analysis of Earthquake Resistant Design Principles Applied in Reinforced Concrete Residential Buildings in Turkey", PhD Thesis, Middle East Technical University, Ankara, Turkey.

Özmen, G. (2004) "Çok Katlı Yapılarda Burulma Düzensizliği", (Excessive Torsional Irregularity in Multi-Story Structures) Teknik Dergi, 15(1), pp. 3131-3144. [online] Available at: http://dergipark. gov.tr/download/article-file/136721 [Accessed: 15 August 2018] in Turkish)

Öztürk, T. (2011) "A study of the effects of slab gaps in buildings on seismic response according to three different codes", Scientific Research and Essays, 6(19), pp. 3930-3941.

https://doi.org/10.5897/SRE10.076

Peña, W. M., Parshall, S. A. (2001) "Problem Seeking: An Architectural Programming Primer", 4th ed., John Wiley \& Sons, New York, USA.

Teddy, L., Hardiman, G., Nuroji, Tudjono, S. (2017) "The effect of earthquake on architecture geometry with nonparallel system irregularity configuration", IOP Conference Series: Earth and Environmental Science, 99, article number: 012004. https://doi.org/10.1088/1755-1315/99/1/012004

Terzi, M., Elçi, H. (2006) "Çerçeve Tipi Betonarme Yapılarda Döşeme Süreksizliklerinin Kesit Tesirlerine Etkisi", (The Influences of the Slab Discontinuities on the Internal Forces at Frame Type Reinforced Concrete Structures) Pamukkale University Engineering College Journal of Engineering Sciences, 12(3), pp. 341-349. [online] Available at: https://www.journalagent.com/pajes/pdfs/ PAJES_12_3_341_349.pdf [Accessed: 15 August 2018] (in Turkish) 